\title{
THE INFLUENCE OF SPEED DRILLS UPON THE RATE AND THE EFFECTIVENESS OF SILENT READING
}

\author{
ChARLES C. PETERS \\ Lehigh University
}

Within recent years the psychology of reading has been intensively studied by a considerable number of investigators, among whom the following persons have made valuable contributions to the subject: Erdmann and Dodge at Halle in 1908, Dodge at Wesleyan in 1900, Dearborn at Columbia in $1906,{ }^{1}$ Whipple at Cornell, Briggs at Columbia, ${ }^{1}$ Pintner, ${ }^{2}$ and especially Huey (1907) in his important work on the Psychology of Reading, and Laing (1909) in "The Teaching of Reading." Since that time a number of experiments have been made on silent as compared with oral reading, the most important of which were the Kansas Silent Reading Tests. One of the products of this study has been the discovery that persons differ very widely in the rate at which they read, the difference being frequently three or four to one, and in extreme cases even more. But the most surprising fact discovered is that rapid reading need not be superficial reading. Indeed all investigators agree that the rapid readers are, as a rule, the most effective readers. Thus Briggs of Columbia had two persons read Silas Marner, one of whom was able to read 156 pages in an hour and the other only 16 . But when ten test questions were given to both on the content of the work read the rapid reader was able to answer them all intelligently while the slow reader could not answer a single one. Klapper quotes from Quantz as follows: "A comparison between the ten most rapid readers and the ten slowest readers shows that the rapid readers remember more of the original thoughts, and that the character of their reproduction is much higher, both generally and with reference to expression and logical content. In the auditory tests the ratio of slow to rapid readers is 14.8 per cent. to 20.7 per cent. in the number of thoughts. In quality the percentages are 48.7 per cent. for slow readers, 60.3 per cent. for fast. The same comparison in the visual tests results as follows: Percentage of thoughts reproduced by slow readers, 14.9 ; by rapid, 24.4. Quality: slow, 48 per cent.; rapid, 73.3

1 See Education, 1912 and 1913, for these articles.

2 Pintwer, Oral and Silent Reading, Journal of Ed. Psy., 4: 333.

(350) 
per cent. The difference in favor of the rapid readers is consequently much greater than in auditory tests, indicating again that rapid readers are, as a rule, of the visual type." 3

In view of this manifest advantage from rapidity in reading a number of these psychologists urge that, in our teaching, we strive to cultivate it. Our present methods of teaching reading, Professor Whipple thinks, are of such a character as to develop plodding habits of reading, and in consequence sluggish habits of thinking. Professor Klapper also thinks that we must get away from our "Fetish of Oral Reading" and work definitely for "(1) speed, (2) accuracy, and (3) direct association between printed symbol and idea." Laing remarks that "All writers agree that through practice the span of attention (an important element in rapidity in reading) may be increased," Briggs urges the seeking of speed, and Dearborn says, "What may be called speed tests ought on this account to have some place in school methods of teaching reading, as well as in other subjects in which alertness of attention is demanded and cultivated."

But that this ability to read more rapidly could be cultivated had never been demonstrated.5 There was some reason to believe that it is a native characteristic rather than one due to training. It was certain that rapidity and mental alertness went together but which was cause and which effect had not been ascertained. ${ }^{6}$ All of the experiments performed by the psychologists were of a static rather than a dynamic character. They took their subjects at a single stage and compared them with others taken also at a single stage. Moreover the experiments were nearly all performed upon adults, only one or two having to do with children as young as nine years old.7 To assume from these static experiments that the recommended speed drills would, under ordinary school conditions, be a factor in developing rapidity and attendant effectiveness was a purely

${ }^{3}$ Teaching Children to Read, page 23.

- Teaching Children to Read, page 23.

8 Professor Freeman quotes an unpublished thesis by K. D. Waldo in defense of this supposition. But Professor Freeman's tables are not sufficiently complete to indicate whether or not precautions were taken by Waldo to distinguish the result of speed drills from that due to such development as is to be expected through a school year. (Psy. of Common Branches, page 90.)

"On one side of this question see Freeman, "Psy. of Common Branches,"pp. 89-90; on the opposite side see Irving King, "A Comparison of Slow and Rapid Readers," School and Society, Nov. 25, 1916, pp. 830-34.

' Recent experiments have, of course, dealt with school children. 
a priori inference, so far as I could learn. No trace could be found of any experiment to determine it. It was to empirically test the actual effect of such effort that the following experiment was planned.

In undertaking the experiment the writer hesitated between two methods of working for speed. Should it be by simple speed drills or should there be an effort to control the fixation points? The Psychology of Reading seemed to favor the latter. It was known that rapid readers differ from slow ones very largely in the number of pauses, or fixations of attention and eye direction, which they make in each line. The slow readers make many and irregular fixations; the rapid readers, few and rhythmic ones. It appeared desirable, therefore, to control the place and the number of fixations per line on the part of the reader. The feasibility of determining these points by some sort of marks, or by sweeps of a pointer, or by appropriate spacing, was considered. In addition to their fewness and regularity thus secured the shortening of the period of these fixations, by some device, to the minimum necessary for comprehension was considered. That these fixations should be as short as possible is indicated by the discovery of Cattell, Quantz and others, that when reading matter is exposed for one one-hundredth of a second more of it can be read than when exposed for a somewhat longer time.

But it was also known that interest in the matter read, and an interest in proceeding as rapidly as possible, will alone drag on the fixation points to a greater distance and make their period shorter. Besides it was not established that there is any one optimum length of interval, the evidence indicating that this interval differs for even the same individual according to the subject matter read. It seemed plausible, therefore, that the eye movements would fall of themselves into their best type of rhythm for the particular individual and for the particular subject matter read if no attempt were made to control them from without. Besides it was feared that such devices as would be necessary to control the fixation points would distract attention so much, particularly at first, as to seriously interfere with reading by the young children who were to be experimented upon. It was therefore decided to make no effort to control fixation points by mechanical devices but to rely upon interest in the matter read and, especially, upon the request to get the matter 
read as quickly as possible, together with such atmosphere about the room as would encourage speed without producing such undue excitement as would lead to superficial reading. It would, however, be worth while to try this same experiment with the added effort to specifically control the number and the nature of the fixation points.

\section{The Experiment}

Our experiment thus narrowed itself down to the specific one of ascertaining the influence upon speed and effectiveness of silent reading from daily speed drills, with oral reproduction, conducted through a period of seven months.

The experiment was carried on in the public schools of Royersford, $\mathrm{Pa}$., during the academic year 1914-15. The writer was at that time supervising principal there. The experiment was made in grades three to six inclusive, though the results of the third grade are not included in the summary of results, for reasons to be discussed later. They are tabulated separately. There were used in the experiment six different teachers and two hundred and seven different pupils. The grades indicated above were chosen because reading receives in them a considerable amount of attention, and because the children here have reached the point in their training where such proportionately great changes in individuality as those of their earlier school years are not to be expected. It was originally the intention to include also grades one and two, but the extreme instability which we discovered in these grades made it advisable to drop them. Our experiment made it necessary to divide these grades into two groups each, as nearly equal as possible. But we soon discovered that, however nearly equal they were in the beginning of the year, forces altogether outside of the experiment might carry them far apart before the year had worn on long when they are so unstable in character as first and second grade pupils necessarily are.

Of the grades that remained there was a teacher for eachthird, fourth, fifth and sixth-in one building, and a teacher for the third and fourth together and a second teacher for the fifth and sixth together in another building. Those that had a teacher to each grade were ideally ordered for an experiment. In each of these the pupils were divided into two groups, as nearly equal in numbers and ability as convenient. Then a test, such as those described below, was given in each room, with all essential 
conditions carefully kept uniform. Papers were then graded in the manner indicated below, and the group which showed the least speed chosen, when feasible, as the one to receive the drill. Exactly the same test was given, at the same time and with the same attendant conditions, in the two rooms in the other building. In these rooms, however, the pupils of each grade were kept as a single group. Thus for each grade there were three groups, two of which were given the speed drills and one of which was not. The effect of the drill was thus sought by comparing the two groups in each grade which had the drill with the one group which did not.

\section{Method of Conducting Drill}

The groups which were not to have the speed drills, and which were to be used as a basis for comparison with those which did have, were dealt with after the usual fashion in teaching reading. The other groups, in addition to their oral reading, were given daily speed drills, without, however, giving a total of any more time to their reading than the other group received. So far as feasible both groups were taught reading at about the same time of day, or else at equally desirable periods. They used the same books and the same degree of enthusiasm was expected to be put into both. The drills were, of course, conducted by the teacher in charge of the class, and ran from November 7th to June 2nd. They were on relatively easy reading matter, and mostly interesting narrative. They occupied ordinarily from five to ten minutes of the reading period. The group as a whole was told explicitly where to begin and how far to read, and were then all set to silent reading at the same time with the exhortation to see who could get it read first. After all, or nearly all, had finished someone was asked to tell the substance of what he had read. If, in this reproduction, he omitted anything he was questioned on it as a guarantee against skimming.

\section{The Tests}

Tests were given to both groups on November 6th, January 20th, April 20th, and June 2nd. It was originally intended to give a test at intervals of two school months but when we came, on this basis, to the third test nearly half of our pupils were out with mumps and it was necessary to hold it over about 
two weeks until most of the students were back. However, as nearly all of the pupils were out the three weeks quarantine period sometime during the second interval, the amount of practice received in it was approximately the same as in the first interval. However, it cut the length of the last interval to six weeks. These tests were conducted by the teachers in charge of the classes. As the teachers had given the drill, and as the tests were of somewhat the same character, it was thought that their conduct of them would be less of a disturbing factor. Besides, the necessity for conducting them all on the same day and at approximately the same hour made it impossible for the experimenter himself to hold them.

In each case the test consisted of two parts, given on successive days. The first of these parts consisted in the reading of a selection of from eighty to three hundred words with written reproduction of the substance of what had been read; the second, of the reading of directions to perform some act and then the carrying out, on the part of the reader, of those directions. For these tests children were taken in groups of six, so as to permit of an exact record of the time required for each individual to complete the reading. Books were kept closed, or papers turned upside down, while the teacher explained carefully what was to be done and taught any new or difficult words that might appear in the selection, without, however, indicating that they were to appear in this reading. When everything was ready all in the group of six were set to reading at the same time and as they finished they so indicated by raising their hands, closing their books or turning over their papers, and permitting the teacher to record the time. Every effort was made to keep all conditions constant during these tests.

The reading selections used in the tests were in every case narrative in form and somewhat easier than the usual reading for the grade in question. This was done to secure maximum interest, to make reproduction relatively easy, and to permit of the certain employment of any speed for which the pupil might have developed the ability. Different selections were used for the different grades. Stories which we believed the children had never read before were used in every test except the last, when lack of suitable material made it necessary to use matter, in one or two of the grades, which they had read not 
less than a year before. Where possible a selection that was complete within the length of a page, or a page and a half, was sought, though we were sometimes obliged to use only parts of stories. We looked for material that was interesting but not so much so as to produce a disturbing amount of emotional strain. Normal print was sought and paragraphs which had their lines broken on account of pictures on the page were avoided.

In the second type of test the task set was in each case the drawing of some object for which directions were given. Here the procedure was the same as indicated above, except that the matter was the same in all the grades, except in the first test when it was somewhat simplified for the lower grades. Care was taken to set for drawing some object which was familiar to every child taking the tests - no easy thing to do, as the experimenter soon discovered. Something was also sought that represented a considerable degree of internal unity, so as to make the execution of the directions reasonably easy, but yet not so much of a unity as to make it possible to draw it without having read all the way through the directions. The directions were extended, by a little padding, to such length as would make it convenient to measure the time without making it so hard to read or carry in mind as to interfere with its purpose. To further facilitate memory a brief review of directions was usually given at the end and invariably the selection closed with some catch sentence, without which the drawing could not be complete, and which would therefore serve as a guarantee that it had been read all the way through. These selections were typewritten, double spaced, and with lines of about seven words in length, such length appearing to about balance the matter as compared to print in books. Care was taken to make all copies alike in all mechanical respects. Three copies were made at a time

\section{DIRECTIONS}

No. 1

Draw a square on your paper. A square is a figure with four straight lines as sides These lines are all of the same length and the four corners are all alike. This ceiling would be a square if it were just as wide as it is long. After you have made the square place a dot right in the middle of it. Be careful to place the dot exactly in the middle. Then draw lines from this dot to each of the corners. That mil take four lines. Be sure to make all the lines straight Remember you are first to draw a square, then place a dot in the middle of it, and then draw lines from this dot to each of the four corners. When you have done this count all the lines and write the number of them on your paper. 
No. 2

Draw a house Make your house two stories high. In the front of the house, on the first story, put a door in the middle and a window on each side. In the upper story put three windows. One of these should be above the door and the others above the windows of the first story. You will find out that this will make your house look best.

Put a fence in front of the house with a gate in it. Mark the path which leads from this gate up to the front door. Remember you are to draw a house, make it two stories high, put a door and two windows below and three windows above, put a fence with a gate in front of it, and mark the path which leads from the gate to the door.

No. 3

Draw a boy's face. Just make a round ring for the head. Not every boy has a round face but a ring will do for this boy. Then put in lines for the nose, the mouth, the two eyes, and the two ears. Also mark his hair. Put some sort of a hat on him. But do not put any body to him. Remember you are to make only a round ring for a head, put in eyes, nose, mouth, cars, and harr, put on a hat, but put no body to the head. W'rite the boy's name under the face.

No. 4

Draw a bridge across a river. We will suppose that no big boats go up and down this river, so we can put as many posts as we please between the ends of our bridge for it to rest upon. Then, you know, a good bridge must have an iron fence along each side to keep people from falling off. Our bridge must have such a fence. Many people, too, cross a bridge, and ours would not look well unless it showed some of them. But you need not try to draw in their faces. Just a straight stroke would do for each man. Put four such men on the bridge in your picture.

\section{No. 5}

Draw a tree as you would see it in winter. You know there are no leaves on the trees in the winter. The leaves grow out in the Spring and drop off in the Fall. Draw five limbs on each side of the trunk of your tree. Make the lower limbs longer than those at the top, as this will make your tree look better. Now, you know, birds often sit on trees Of course, in winter most birds have gone away, but a few stay here. So mark on your tree three small birds where you think they would sit.

and the same number of carbon copies given to each group. Samples of these directions accompany this paper. ${ }^{8}$

\section{Marking the Papers}

The teachers graded the papers. In the reading selections the experimenter indicated the number of thoughts which the selection seemed to contain, and this was made the basis for assigning a percentage to each pupil. The papers were marked for quality of reproduction as well as quantity (in separate grades) but the element of judgment entered so largely into the marks for quality, with the attendant unreliability for scientific purposes, that no use was made of these marks, only the ones for quantity appearing in the tables. In the lower grades it was an easy matter to separate a selection into its distinct thoughts and to find these thoughts either present or absent in

${ }^{8}$ As this experiment was conducted before the Kansas Silent Reading Tests we could not profit by suggestions regarding technique which these tests have made. 
the papers and mark them accordingly. In the higher grades, however, this could not be done with nearly as great definiteness and here the teachers were forced to rely partly upon an estimate of the completeness of the paper. This may have introduced a varying condition when the group under one teacher was compared with that under another, though it probably counted for little when both groups were under the same teacher. In the drawing papers grades were also assigned to the papers according to the extent to which the pupil had understood and followed the instructions. Thus the work of each pupil.was recorded as to time, which indicated the speed with which he could read, and as to quantity of reproduction, which indicated the effectiveness of his reading. In the tables which follow speed is reduced to number of words per minute.

\section{Computation of Results}

The first tests, given at the beginning of the experiment (Nov. 6 and 7) were used to ascertain the degree of equality between the two groups-the "drill" and the "no-drill" groups; the others to measure their degree of equality as the experiment proceeded. All pupils who were absent in any one of the tests were eliminated, except that in two cases where pupils had missed only one half a test (for example the drawing, but not the reading) their grades were computed, on the basis of their results in other tests as compared with the average, and inserted. All persons who were abnormal-either unusually rapid or unusually slow-were also eliminated. In addition the whole of the third grade was eliminated in making the summaries. This was because the drill group in the room with both groups was so small as to make its results unreliable (only five, after eliminations) and because it would therefore have been necessary to depend almost entirely upon a drill group under one teacher and a no-drill group under another. With children so susceptible to the varying abilities of teachers as third grade pupils it seemed best not to include this grade in the general summaries. The results in this grade are given in the tables, though not included in the summaries.

After eliminations there remained, out of the original two hundred and seven, one hundred and thirty-seven in the fourth, fifth and sixth grades and forty-three in the third grade. Thus twenty-seven were eliminated on account of absence or of some abnormality. 


\section{RESULTS}

The following summaries indicate the results of the four tests. The summaries are also shown in graphical form on charts accompanying this paper. In indicating the rooms the numbers refer to grades, $a$ and $w$ distinguish buildings ( $w$ had both drill and no-drill groups while a had only drill groups), and $\mathrm{d}$ and n stand respectively for "drill" and "no-drill." All averages are weighted.

TABLE 1

Speed in Reading

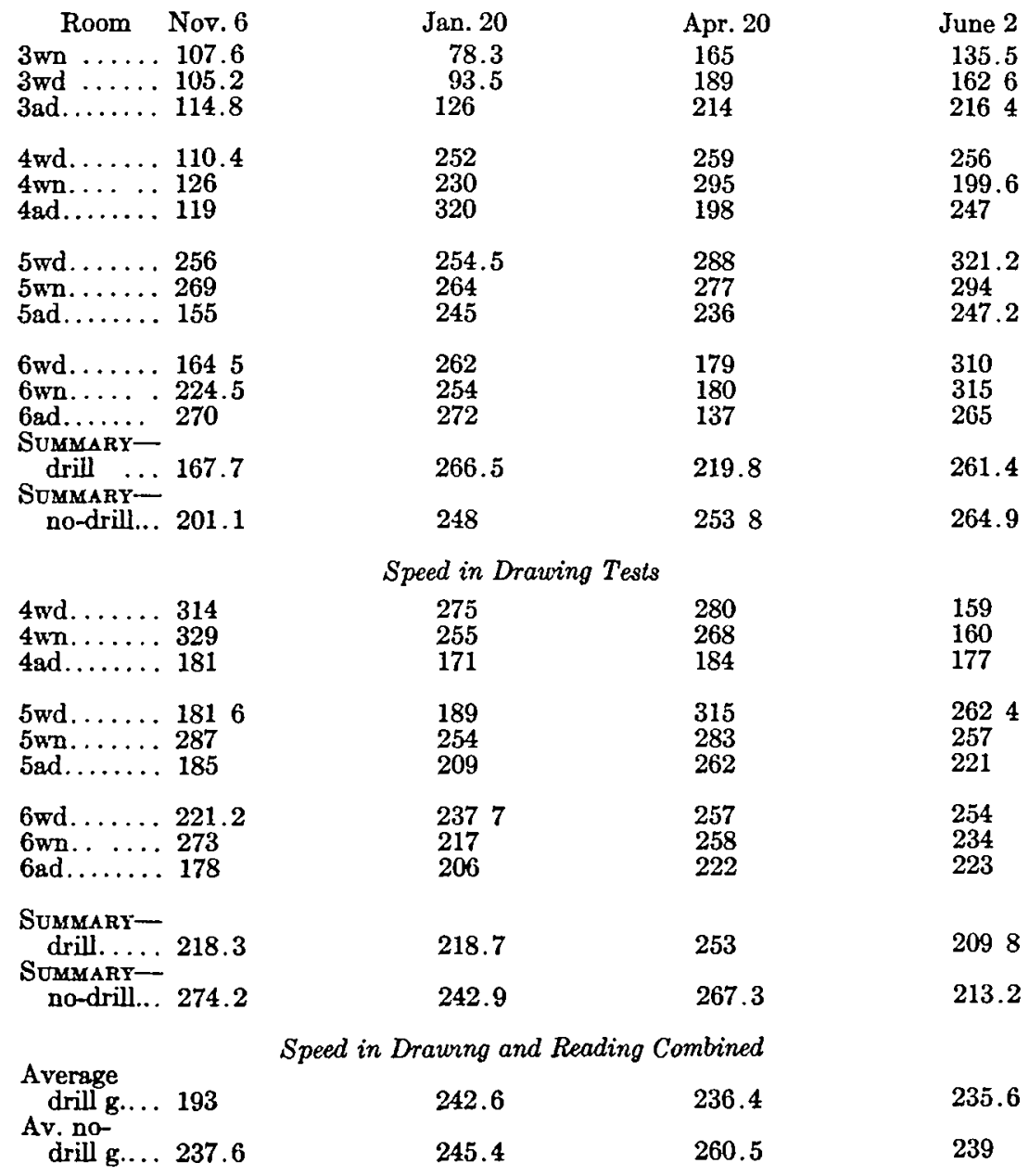


Quantily of Reproduction in Reading

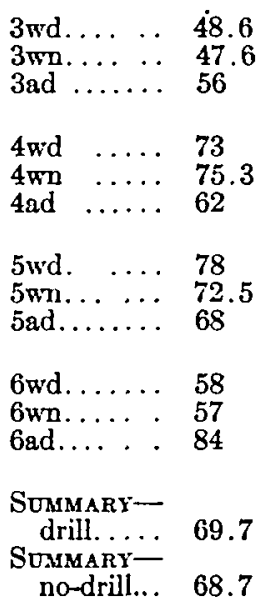

$4 w d . . . \ldots 73.9$

4 wn ..... 64.4

4ad ....... 74.7

5 wd $\ldots \ldots 95$

5wn. . . 944

5ad....... 84

6wd. .... 96.7

$6 \mathrm{wn} \ldots \ldots 99$

6ad........ 92

Sommary-

drill .. 84.4

SUMMARY-
no-drill...
91.4

61

58

80

71.1

84.4

65.7

62

70

63

58

81

722

64.2

Quality in Drauring

62.9

70.1

94

95

98.2

78

96

93

84

83.4

85.9
885
77

65.8

78.6

78

78

90

88

87.6

67.3

65

50

76.4

77.1
81

80.6

70

89.2

71

824

823

73

92

852

734

814

74

892
. 6

89.2

921

96

91

865

92.5

883

92.1

96

922

907

Quality, Reading and Drauing Combrned

$\begin{array}{ll}\begin{array}{c}\text { Average } \\ \text { drill g.... }\end{array} & 77 \\ \text { Av no- } & \\ \text { drill g.... } & 75.3\end{array}$

78.8

81.5

86.6

75

80.6

856

The following table shows the relative gain or loss of the drill group as compared with the no-drill group and their distribution throughout the three intervals through which the experiment ran: 
TABLE II.

No. of cases of relative gain in speed ..... . 16

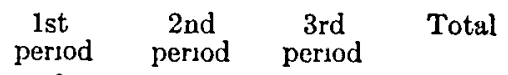

No. of cases of relative loss in speed. . ... . 2

No. of cases of relative gain in quality .... . 5

No. of cases of relative loss in quality ..... 7

No. of cases of simultaneous gain in both speed and quality $. \ldots, \ldots \ldots, \ldots, \ldots$

No. of cases of simultaneous loss in both speed and quality .... . . .... ... ... 2

No. of cases of inverse relation in speed and quality.................... 5

$\begin{array}{lll}4 & 8 & 22 \\ 8 & 4 & 14 \\ 3 & 5 & 13 \\ 9 & 7 & 23 \\ 2 & 4 & 11 \\ 7 & 3 & 12 \\ 3 & 5 & 13\end{array}$

The above table shows a surplus of cases of gain over cases of loss in speed and hence speaks for the value of the speed drills from that standpoint. It will be noticed that the number of cases of relative gain decreases from the first period to the third while the number of cases of relative loss increases. This is due to the fact that the gains were made largely in the early part of the training period. Thereafter, if the drill group failed, at any test period, to hold all of the advantage which the last test indicated that it had gained the relative drop counted as a loss, even though, compared with the initial relation between the groups, the drill group still retained a significant net gain. Consequently these intermediate relative gains and losses have little significance. They show only where the gains are just about overbalanced by losses. The real story is told by a comparison of the conditions at the beginning with that at the end of the whole training period. In consequence the following table represents the situation more correctly. It gives the number of cases of relative gain or loss in the several periods compared always with the relative standing of the groups at the beginning of the experiment.

period period period

No. of cases of relative gain in speed. .... 10

No. of cases of relative loss in speed ...... . 2

No. of cases of relative gain in quality...... 5

No. of cases of relative loss in quality..... . 7

No. of cases of simultaneous gain in both .... 5

No. of cases of simultaneous loss in both... . 2

No. of eases of inverse variation.......... 5

The single case of net relative loss in speed in the last period on the part of the drill group as compared with the no-drill group was an instance where a group in one building, under one teacher, 
was compared with a group in another building under another teacher, and where, consequently, conditions were unpropitious for experiment. Even there the loss was very slight.

The following table summarizes in convenient form the results of the experiment. The relation between the groups at each stage is expressed in per cent., in which the work of the no-drill group is used as the base. Thus under speed in reading the table indicates that the drill group could read $83.8 \%$ as rapidly as the no-drill in the beginning, $107.5 \%$ as rapidly after two months, etc. This table shows a relative gain of $18.7 \%$ in speed but a trifling loss in quality as the result of the speed drills.

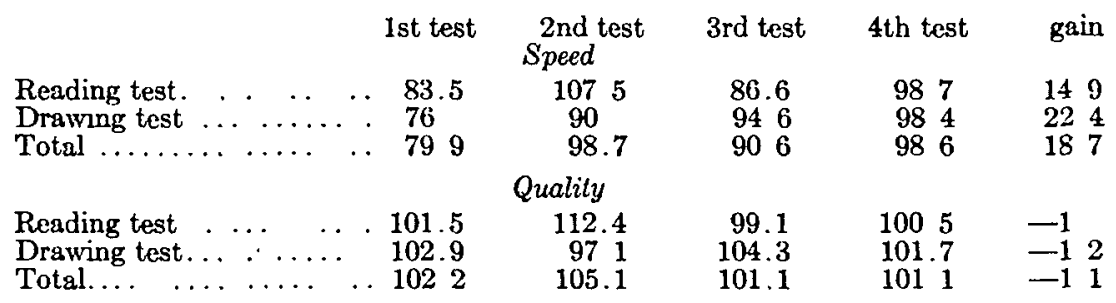

\section{Observations on the Experiment}

1. The comparison between groups in different buildings, and under different teachers, is by no means ideal for experiment. It does not insure that all factors besides the one experimented upon remain constant. Altogether apart from the effect of the specific drills pupils may, under such diverse conditions, make different degrees of progress. Hence those cases in this experiment which compare two groups under the same teacher are the more trustworthy.

2. It was not possible to keep conditions absolutely constant even through the tests. For these tests consumed over an hour in time, and the degree of fatigue doubtless varied somewhat within as long a period as that. Hence the group tested first may have been either more or less alert than the group tested second. Besides the fact that the test had been running for some time in the room would tend to make it monotonous, or otherwise different, and this may have affected the results. It occurred to me afterwards that this disturbing factor might have been reduced to a minimum by taking sections alternately out of the drill and the no-drill groups, instead of testing all of the one group first and all of the other group later. This, however, was not thought of in time. 

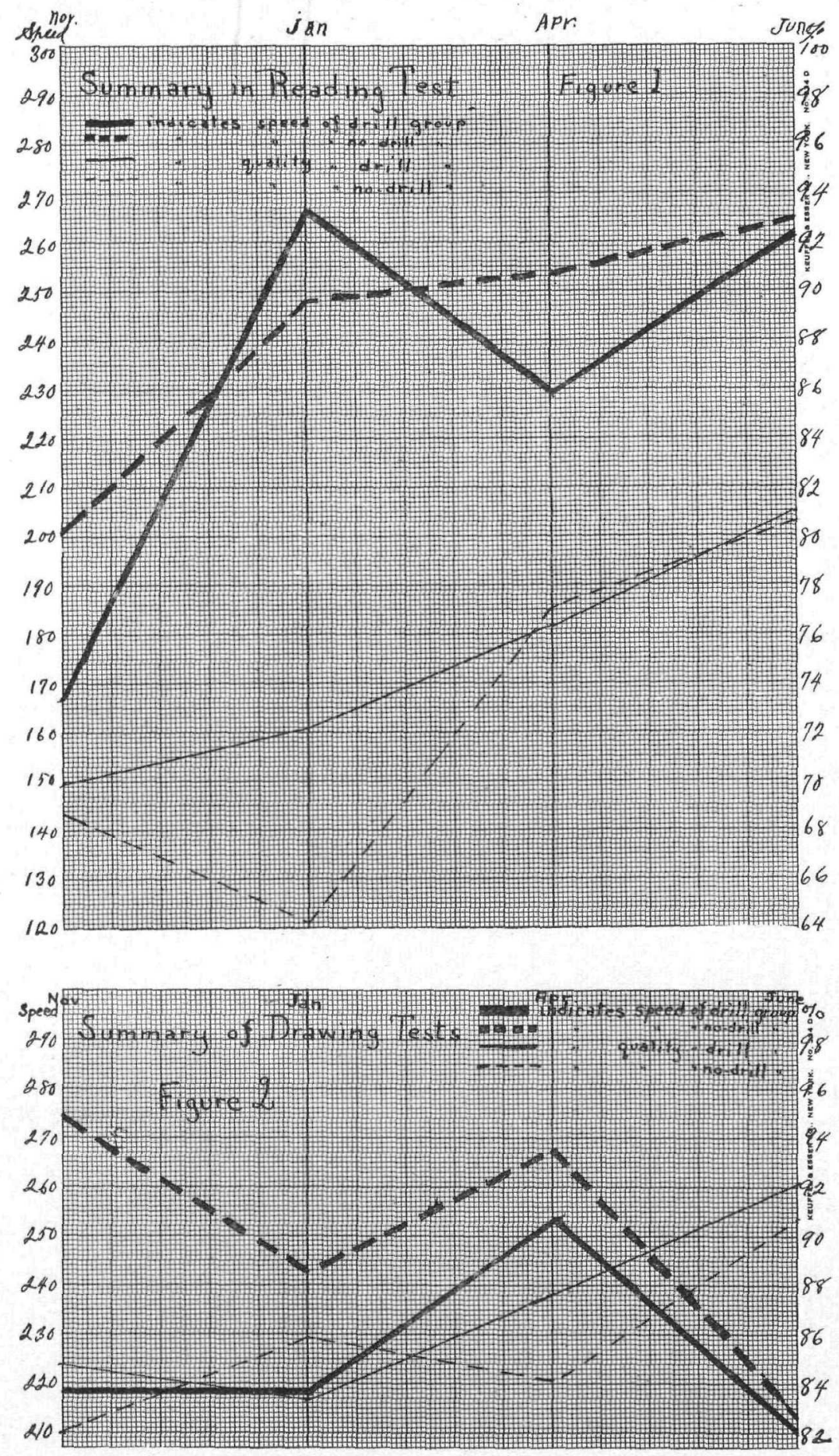

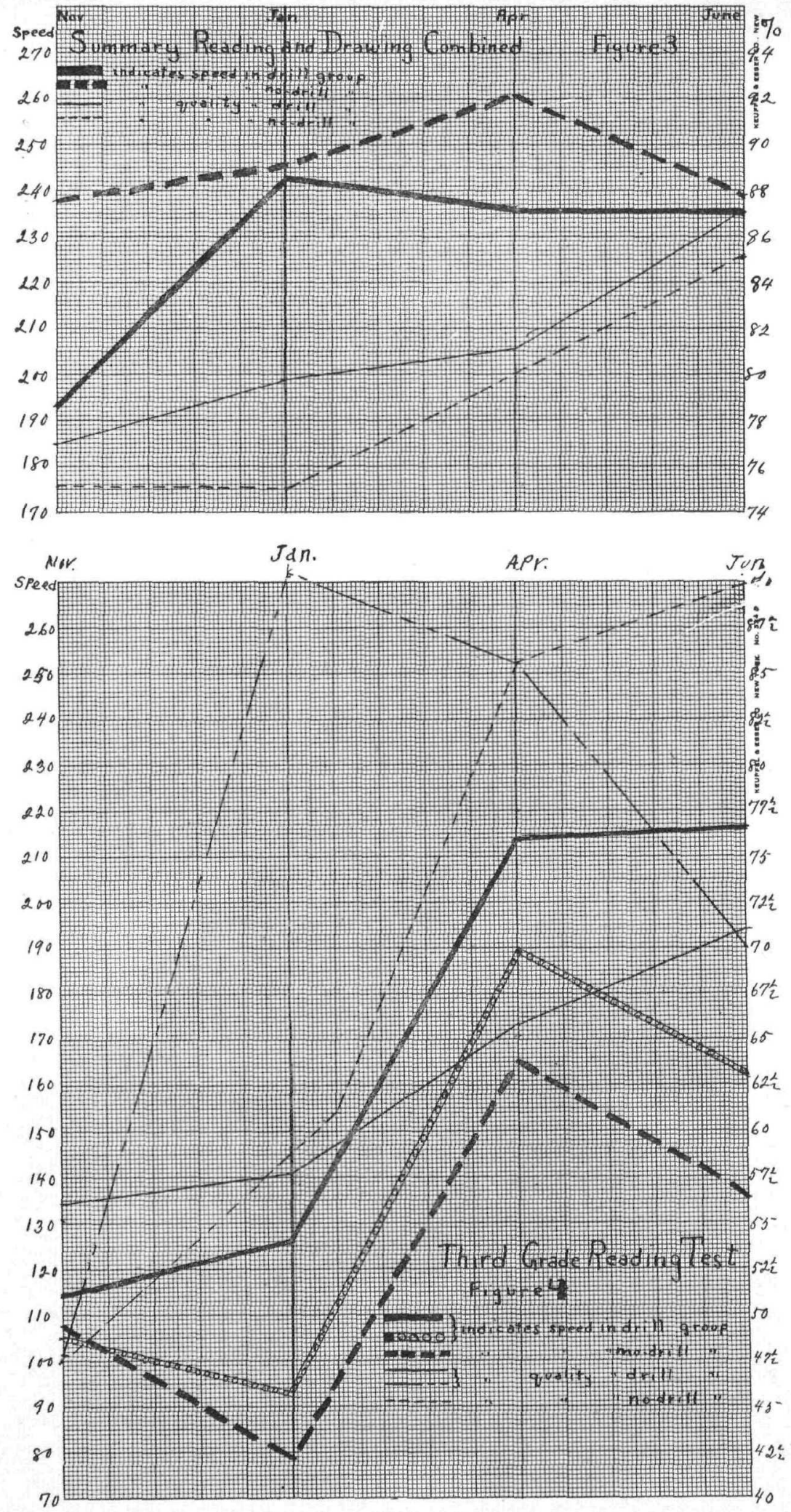
3. A peculiar departure from the general trend of the results of the experiment occurs in the showing of the third test. Here the drill group loses on the average almost as much as it had gained in the first period and simultaneously loses in quality. There are eight cases of relative loss in speed in reading against four of gain, while in the other two periods this proportion is reversed or better. The quality fares almost equally badly. Indeed there are seven cases of simultaneous loss of speed and quality here while there were only two in the first period and three in the last. It was during the preceding period that a large proportion of the pupils were out with contagious diseases, but a study of the agrgegate number of days missed by both groups showed that the no-drill group missed not less but slightly more time than the drill group, so that that could not explain the matter. Another factor which might possibly have some bearing was the fact that the teacher in the room departing most widely from the expected was called out of the room for a short time while the test was in progress, but, from studying carefully the attendant conditions, we could not convince ourselves that that could have seriously affected the results. But I suspect that the true explanation lies in a difference in our mode of approaching this test as compared with the others. In earlier tests pupils were allowed to read normally. They were not urged to go rapidly. In this third test, however, by the advice of the seminar, ${ }^{\circ}$ all pupils were urged, when they sat down to the test, to read as rapidly as possible. It is true that this exhortation was given to both groups but, in as much as it was new to the no-drill group and an everyday occurrence to the drill group, it may have acted as a more effective spur to the former than to the latter, and thus unbalanced the conditions. If this is the correct explanation it emphasizes two things: first, the great extent to which both speed and effectiveness of reading respond to added effort, and, second, the extreme caution which an experimenter must exercise to keep conditions constant in his two groups. What appears to be but a trivial matter may really be of enough consequence to vitiate the whole experiment.

4. An examination of the data given for the third grade (not included in the summaries) shows a decided gain in speed (22.5\%)

9 The seminar in Educational Research conducted by Professor Yocum at the University of Pennsylvania, of which the writer was a member at the time. 
but also a considerable loss in quality (14.7\%). This may indicate that the habit of reading rapidly is most easily formed at this early age, but that this rapidity is gained at the expense of accuracy, or it may be due merely to the untrustworthy conditions which attended this part of the experiment, as noted before.

5. This experiment has not confirmed the doctrine that increase in speed will carry with it, in any given individual, also increase in effectiveness. ${ }^{10}$ It is not improbable that differences in reading speed are only indicative of more fundamental differences ${ }^{12}$ differences in sluggishness of thinking - and that the best that can be done, as the result of speed drills, is to bring up the speed more nearly to the possibilities of the particular individual, but that the naturally slow reader can not be developed into a rapid one without impairing his effectiveness. Whether, and how, slow readers differ from fast ones in their mental characteristics needs to be determined by experiment.

6. It is not improbable that an added effort to control the mechanics of reading - that is eye movements - would show even better results in speed. It is also probable that it is worth while to teach children to "skim." That must be determined by separate experiments. But the present investigation, showing a relative improvement of $18.7 \%$ in speed, without injuriously affecting the quality, as the result of the drills, strongly suggests the advisability of giving speed drills as a part of the teaching of reading.

\footnotetext{
${ }^{10}$ For an account of an experiment which seems to confirm this one see Irving KING, A Comparison of Slow and Rapid Readers, School and Society, Nov. 25, 1916, pp. $830-4$.

i Thomdike found this true of speed and accuracy in arithmetical processes. See Journal of Educational Psychology, Feb., 1914.
} 